\title{
Exploring the Impact of Self-Directed Team Learning in an Air Traffic Control Environment
}

\author{
Jacobus G. Maree \\ Christiaan G. Joubert \\ Mike van der Linde \\ Paul J. van Staden \\ University of Pretoria
}

Address correspondence to Professor Jacobus G. Maree, Faculty of Education, University of Pretoria, 0001 Pretoria, South Africa. E-mail: Kobus.Maree@up.ac.za.

\begin{abstract}
Experienced military air traffic controllers $(25$ respondents, males $=15$, females $=10$, years of experience $=$ less than one year $=5$ respondents, more than one year but less than three years $=11$ respondents and more than three years $=9$ respondents) participated in this study to determine whether self-directed team learning exists within their air traffic control teams and to understand the impact of self-directed team learning on the air traffic control work environment. Data on self-directed team learning and learning approaches were collected using a Self-directed Team Learning Questionnaire (SDTLQ) and a Learning Approaches Questionnaire (LAQ). These data were analysed using an inductive reasoning mode for qualitative data analysis and quantitative data analysis followed a supporting deductive reasoning mode. Triangulation as a technique was used to determine whether multiple sources of data agreed and to obtain better, cross-checked insights (Burgess, 1985). Results revealed that these air traffic controllers and air traffic control teams investigated in the study do indeed function within self-directed working, training and learning environments. The quality of team performance was influenced by self-directed team learning initiatives. Furthermore, the quality of self-directed team learning relied upon the effectiveness of air traffic control team performances.
\end{abstract}

\section{Keywords: air traffic control, continuation training, human factors, self-directed team learning, teamwork}

Team learning is cyclical and ongoing; changing team structures take time and are influenced by a specific team's challenges and desires (Ober, Yanowitz \& Kantor, 1996). Team learning is strengthened by making more of team members' private meaning structures accessible so that they can influence other team members, as well as making the collective meaning structures accessible so that they can be tested and altered (Dixon, 1994). Adult learners typically engage in self-directed learning. For instance, adult learners tend to readily apply certain schemata or meaning systems composed of sets of beliefs or assumptions based on their experiences (Mezirow, 1981; Silverman \& Casazza, 2000). These schemata form filters through which new information is received and interpreted (Silverman \& Casazza, 2000). Equally important to experience are the expectations and agendas which adult learners bring to their learning experience (Rogers, 2002). Adult learners become increasingly more self-directed when given appropriate learning tools, resources, experiences and encouragement (Brockett \& Hiemstra, 1991). Self-directed team learning brings together strategies from several educational streams, thereby allowing learners to meet their own individual learning needs and those of the team by being actively involved in critically analysing, reflecting on, and responding creatively to their situations (Hammond \& Collins, 1991). Thus self-directed team learning is not simply the sum of individual and team learning objectives. Self-directed team learning is made up of an amalgamation of individual and team objectives. The self-directed team in the air-traffic control environment is important. Considering that two or more air traffic controllers interact dynamically and interdependently within assigned specific roles, functions and responsibilities-they have to adapt continuously to each other to ensure the establishment of a safe, orderly and expeditious flow of air traffic (Barbarino \& Isaac, 2000). Research conducted by Smith-Jentsch, Zeisig, Cannon-Bowers \& Salas, (1997) to determine the importance of teamwork in air traffic control, supports the notion that air traffic controllers demand and value effective teamwork.

Air traffic control teams and the individual members of the team are characterised by the level of competencies that they have, relative to what would be required to provide safe, orderly and effective air traffic control services. The design and development of air traffic control operational training and learning need to focus on specific deficiencies in existing and/or identified individual and/or team performances. Learning in this regard is evident in the performance of air traffic controllers with reference to their ability to anticipate events, solve problems fast and maintain a level of skilled performance/expertise with less effort (MacLeod, 2001).

\section{Self-Directed Team Performance in the Air Traffic Environment}

Air traffic control requires specific human behavior-the application of a skill; being able to control air traffic. Behavior requirements include flexibility of the human operator (controller), capability to deal with unexpected situations, creativity and a safety consciousness (Leroux, 1995). Research conducted by Smith-Jentsch et al. (1997) to determine the importance of teamwork in air traffic control, supports the notion that air traffic controllers demand and value effective teamwork. Furthermore, the data indicated that the more experienced a controller was, 
the more strongly he/she believed in the importance of teamwork (Smith-Jentsch et al., 1997). Self-directed work teams are multiskilled and team members are encouraged to continuously develop skills and knowledge (Irwin \& Rocine, 1994). They not only do the work, they also take on the management of the work (Williams, 2004). There must be interdependence and joint responsibility for outputs if there is to be a self-directed work team (Williams, 2004).

\section{Continued Learning}

Within an advanced technology and fast changing work environment the continuation training contribution can be qualified in terms of self-directed incremental learning and unlearning (Meyer, 1999). Continuation training thus stimulates incremental learning (building upon existing knowledge and skills) and ensures that required unlearning takes place (obsolete knowledge is discarded to make room for something new). Self-directed learning, as a means to facilitate continuation training, ensures that real learning takes place in teams when team members learn from each other, learn from their achievements and mistakes, and continuously invest in learning optimization opportunities.

When reflecting upon the value of air traffic control continuation training it is observed that continuation training is an effective means to ensure the sustainability and survival of effective self-directed team learning and performance. Continuation training provides performance stability in an environment that is characterised by uncertainty, rapid change and the continuous pursuit of safety and excellence (Meyer, 1999).

\section{Goals of the Study}

In this study we examined the nature, characteristics and impact of self-directed team learning in the air traffic contro workplace. The primary focus of the study was on exploring the impact of self-directed team learning in an air traffic control environment. The collection and analysis of self-directed team learning data addressed the following questions: First, does self-directed team learning impact on the air traffic control work environment? Second, what is the nature of self-directed team learning impact on the air traffic control work environment?

Identifying and understanding the role of self-directed team learning within the scope of workplace performance, measuring dynamics and identifying and describing individual and collective (team) views, creating deeper understanding of primary and secondary modes of learning by self-directed teams, and understanding how a team sustains continued learning in the workplace served as focus areas.

\section{Method}

\section{Mode of Inquiry}

A mixed-method strategy was opted that combined quantitative and qualitative techniques and data analysis in order to add depth and detail to findings (McMillan \& Schumacher, 2001; Swanson \& Holton, 1997; Tashakkori \& Teddlie, 1998). A mixed-method approach allowed for the elaboration, enhancement, illustration and clarification of the results of one method with that of another (Tashakkori \& Teddlie, 1998). This mixed-method strategy is illustrated by the typology quan + QUAL. These abbreviations indicate that quantitative (quan) and qualitative (QUAL) methods were used. The upper case denotes the priority given to the qualitative orientation (Teddlie \& Tashakkori, 2003).

\section{Participants and Setting}

A convenience sample of 25 selected team members from three air traffic control centers (accessible population: ca. 500 air traffic controllers in South Africa) (25 respondents, males: 15, females: 10; years of experience: less than one year: five respondents; more than one year but less than three years: 11 respondents; more than three years: nine respondents) participated in the study. The air traffic control centers were comparable in terms of air traffic management structures, air traffic control disciplines and air traffic control rules and practices employed. These similarities allowed for comparison of intra-team, inter-team and consolidated results from both a qualitative and quantitative perspective.

\section{Instruments and Procedure}

Interviews and focus group discussions were used to collect the data with regard to what extent team members and teams observe or do not observe self-directed team performance and team learning practices identified in the literature review. Use of one-to-one interviews allowed us to construct everyday reality in the interview, whilst focus group interviews created opportunities for transactions between members themselves. One-to-one interviewers constructed data, whilst participants (focus group interviews) allowed researchers to explore the data still further (Miller \& Dingwall, 1997). Individual interviews specifically attempted to gain a deeper understanding of the role of the individual in the team learning initiative, levels of intentional and unintentional learning, contributions from other team members with reference to learning, and the impact/value of self-directed team learning. Focus groups provided access to: shared individual and team learning experiences; techniques used to learn; comments relating to the role of the team in terms of intentional and unintentional learning; value and contributions from different team members and team roles; and the perceived value of the learning focus.

Participants also completed the Self-directed Team Learning Questionnaire (Joubert, 2006). The Self-directed Team Learning Questionnaire is a measure used to accumulate qualitative data such as descriptions of experiences from controllers and quantitative data that allowed for measurement of self-directed team performance data and self-directed team learning data. Self-directed team performance and self-directed team learning were thus identified and documented as subsidiary topics that related to the primary objective of this questionnaire. The Self-directed Team Learning Questionnaire (SDTLQ) allowed for categorical data, continuous data and intra-team and inter-team comparisons (Table 1). Team performance activities allowed us to determine whether learning opportunities were found in defined team activities. Individual reflection presented an opportunity to investigate individual's reflective practices. It was considered to be important because reflection promotes self-awareness and social awareness, supports adult education principles, improves learning, links theory to practice, and stimulates self- and peer-evaluation. Teamwork performance measures allowed the researcher to identify indicators that the desired air traffic control operational and organisational outcome had been met. Team performance dynamics illustrated how learning was influenced by different team dynamics and individual differences. Individual learning preferences indicated how situational influences and team learning initiatives were influenced by different behaviours. Learning participation created an opportunity to identify initiative(s) that provided work performance information/feedback for personal self-evaluation. Indi- 
Table 1

Self-directed Team Learning Questionnaire Performance and Learning Criteria

Self-directed Team Performance
Team work characteristics
Self-efficacy
Teamwork performance measures
Individual reflection
Team performance activities
Team performance dynamics
Self-directed Team Learning
Individual learning preferences
Learning participation
Individual workplace learning orientation
Workplace training design
Workplace training implementation
Workplace training evaluation
Operational training characteristics
Continuation training characteristics
Workplace learning environment
Team learning facilitation

vidual workplace learning orientation allowed us to determine to what extent effective self-directed adult learning was linked to an external locus of control that favoured dependency. Workplace training evaluation identified those role players that assumed responsibility for workplace training evaluation. In the case of operational training characteristics, adaptability and shared mental models were considered to be key requirements for the members of an air traffic control team. Continuation training characteristics provided us with a different view relating to self-directed team learning. Defined continuation training characteristics were investigated in this case. Workplace learning environment investigated whether functional self-directed adult learning environments were dependent upon intentional/formal and/or unintentional/informal learning interventions. Team learning facilitation identified how team learning was influenced by defined interfaces.

Participants also completed the Learning Approaches Questionnaire: LAQ (Schaap, 2000). The LAQ is a measure of learning strategies and the situational nature of learning. This questionnaire allows for measurement of learning approaches in terms of learning content, consisting of deep approaches, achievement approaches, surface approaches and self-efficacy (Table 2). It also integrates dependent, independent, cooperative and competitive learning approaches in terms of social orientations. Alpha-reliability coefficients calculated for the LAQ illustrated acceptable reliability (varying between 0.744 and 0.928). Reliability statistics confirm acceptable reliability coefficients for all $L A Q$ dimensions.

\section{Data Analysis}

Qualitative data analysis followed an inductive reasoning mode and quantitative data analysis followed a supporting deductive reasoning mode. An abstract descriptive synthesis of the data emerged as a result of the inductive analysis approach utilized. A technique of comparing and contrasting, as suggested by McMillan and Schumacher (2001) was used to identify segments that emanated from individual interviews and focus group interview data.

Questions asked during individual interviews were: (1) Explain with the aid of examples how teamwork influences the outcome of the air traffic control service provided by your centre? This question allowed the team members to explain how self-directed teams plan learning, use resources to learn, and what learning strategies were employed; (2) Explain with the aid of examples how learning from air traffic control teamwork experiences influences your own performance? This question created an opportunity to determine individual practices and consequences achieved, as a result of continued evaluation of learning goals, learning activities, personal demands and concerns, and perceptions; and (3) Explain with the aid of examples how learning from experience influences air traffic control teamwork? This question allowed for an assessment of dynamics, associated with self-managed work team activities and workplace learning, in the air traffic control environment.

Questions asked during group interviews were: (1) What can a team member, joining the air traffic control team, expect from the team? Responses allowed for an assessment of teamwork skills, the team's ability to share knowledge and the team members' attitude; (2) How is individual and collective learning

\section{Table 2}

Learning Approaches Described by the Learning Approaches Questionnaire

\begin{tabular}{|c|c|c|c|c|c|c|}
\hline \multicolumn{7}{|c|}{ Learning Approaches in Terms of Learning Content (LAQc) } \\
\hline \multicolumn{2}{|c|}{ Deep approach (DA) } & Achievement approach (AA) & & \multicolumn{3}{|c|}{ Surface approach (SA) } \\
\hline $\begin{array}{l}\text { Strategy } \\
\text { (DS) }\end{array}$ & $\begin{array}{c}\text { Motive } \\
\text { (DM) }\end{array}$ & $\begin{array}{l}\text { Strategy } \\
\text { (AS) }\end{array}$ & $\begin{array}{c}\text { Self-Efficacy } \\
\text { (SE) }\end{array}$ & $\begin{array}{l}\text { Strategy } \\
\text { (SS) }\end{array}$ & $\begin{array}{l}\text { Motive } \\
\text { (SM) }\end{array}$ & $\begin{array}{c}\text { Fear of failure } \\
\text { (FF) }\end{array}$ \\
\hline \multicolumn{7}{|c|}{ Learning Approaches in Terms of Social Orientations when Learning (LAQs) } \\
\hline & lent (DEPEN) & Independent (INDEPEN) & \multicolumn{4}{|c|}{ Inter-dependent } \\
\hline
\end{tabular}

Note. Schaap (2000) 
planned and executed at your air traffic control centre? This question provided an opportunity to determine whether collective mental models were also explained by investigating outcomes associated with self-directed team learning (including the cognitive, affective and connotative outcomes and associated communication forms); and (3) How can air traffic control team learning at your centre be improved?

Data were organized; evaluated and categorized for informational adequacy, credibility, and usefulness. We subsequently looked for, and recorded, plausible explanations and interpretations. Identified segments were presented as key descriptive terms, subcategories and categories that addressed:

1. team performance;

2. team learning; and

3. continued learning.

We triangulated data to add to the richness of understanding data (Flick, 1998). Because the Shapiro-Wilks tests for normality suggested a normal distribution for the differences for each team, two-sided Student t-tests were used to test the nul hypothesis that the mean difference between Self-directed Team Performance (SDPM) and Self-directed Team Learning (SDLM) equaled zero against the alternative that the mean difference was unequal to zero.

Written permission was obtained from the relevant authorities and from the persons who participated, and the assurance was given that no individual would be identified. For the sake of confidentiality, all information that could identify an individua was disguised or omitted. Ethical measures to ensure the research participants' well-being were implemented throughout the study. The questionnaires were administered and interviews conducted during 2006.

\section{Results}

\section{Team Performance Effects}

Table 3 presents the descriptive statistics for differences between self-directed team learning and self-directed team performance scores (means, $p$-values, and effect size).

\section{Team Learning Effects}

Table 4 presents correlations between certain learning approaches (considering learning content and social orientations when learning) and certain self-directed team results (considering self-directed team performance and self-directed team learning).

\section{Continued Learning Effects}

Table 5 presents ANOVA and post hoc comparisons between the three teams regarding continuation training.

\section{Discussion}

As can be seen from Table 3, for teams 1 and 3, the null hypothesis (which stated that no difference existed between the pair of variables tested) was rejected $(p<.05)$. However, this was not the case for team 2. A relationship existed between self-directed team learning and self-directed team performance for Teams 1 and 3. In team 1, a cooperative interdependent learning approach within a social learning orientation was found that supported self-directed performance and learning. In the case of team 3, a positive relationship was demonstrated between a deep learning approach and an independent learning approach. These were found to be supportive of self-directed team performance and self-directed team learning. The findings in Table 3 suggest that some air traffic controllers valued effective self-directed teamwork that led to desired air traffic control operational outcomes. A summary of self-directed air traffic control team performance impact indicators as SDTLQ measures of teamwork activities and performance reflection highlighted these teams' shared professionalism in upholding and safeguarding air traffic control standards and processes in continuous pursuit of aviation safety objectives as well as employment of self-directed learning routines (see also Cannon-Bowers, Salas \& Converse, 1993; Smith-Jentsch et al., 1997).

These data suggest that supportive learning approaches sustained self-directed team learning and enhanced self-directed team performances.

Statistical significant correlations (Table 4) between certain learning approaches (considering learning content and social orientations when learning) and certain self-directed team results (considering self-directed team performance and self-directed team learning) were valuable and supportive of qualitative findings. The findings in Table 4 suggest that formal/intentional continuation training practices were used by air traffic control teams to address task-specific knowledge, skills and attitudes in a similar and cooperative manner. Impact indicators related to these formal air traffic control continuation training activities were explored in terms of contributions to continued aided learning and situational awareness in support of air traffic control knowledge, skills and attitudes. These air traffic control continuation training results were found to be not fully aligned to the views of Smith-Jentsch, Kaigar, Salas \& Cannon-Bowers (1999) and Salas, Bowers and Edens (2001) due to a perceived partial exclusion of human factors content from continuation training. It was also found that continuation training was managed generally in a formal/intentional manner,

Table 3

Two-sided Student t-tests for Testing Whether The Mean Differences between Self-Directed Team Learning Means and Self-Directed Team Performance Means

\begin{tabular}{|c|c|c|c|c|c|c|c|}
\hline \multicolumn{2}{|c|}{ Team ** } & \multirow{2}{*}{$\begin{array}{c}\begin{array}{c}\text { Sample } \\
\text { size }(n)\end{array} \\
9\end{array}$} & \multirow{2}{*}{$\begin{array}{c}\begin{array}{c}\text { Mean } \\
\text { difference }\end{array} \\
0.117\end{array}$} & \multirow{2}{*}{$\begin{array}{c}\begin{array}{c}\text { SD of } \\
\text { difference }\end{array} \\
0.14\end{array}$} & \multirow{2}{*}{$\begin{array}{c}\text { t-statistic } \\
2.46\end{array}$} & \multirow{2}{*}{$\begin{array}{l}p \text {-value } \\
0.0391^{*}\end{array}$} & \multirow{2}{*}{$\begin{array}{c}\text { Effect size } \\
0.63\end{array}$} \\
\hline 1 & Team 1 & & & & & & \\
\hline 2 & Team 2 & 7 & 0.088 & 0.22 & 1.07 & 0.3248 & 0.31 \\
\hline 3 & Team 3 & 9 & 0.349 & 0.17 & 6.02 & $0.0003^{\star}$ & 1.38 \\
\hline
\end{tabular}

Note. * Statistically significant at the $5 \%$ level of significance; ** These three teams represented the different air traffic control centers 
Table 4

Spearman Zero Order Correlation Coefficients between Learning Approaches (LAQs) and Self-Directed Team Performance (SDPM) and Self-Directed Team Learning (SDLM) with corresponding p-values

\begin{tabular}{|c|c|c|c|c|}
\hline \multirow[b]{2}{*}{ Team } & \multirow[b]{2}{*}{$\mathrm{n}$} & \multirow[b]{2}{*}{ Learning Approaches Questionnaire Description } & \multicolumn{2}{|c|}{$\begin{array}{l}\text { Self-Directed Team } \\
\text { Learning Questionnaire }\end{array}$} \\
\hline & & & SDPM & SDLM \\
\hline Team 1 & 9 & $\begin{array}{l}\text { Cooperative interdependent learning approach in terms of social } \\
\text { orientation }\end{array}$ & $\begin{array}{l}r=0.9613 \\
p<0.0001^{*}\end{array}$ & $\begin{array}{l}r=0.7352 \\
p=0.0240^{*}\end{array}$ \\
\hline \multirow[t]{6}{*}{ Team 2} & 7 & Deep learning approach strategy in terms of learning content & $\begin{array}{l}r=0.4304 \\
p=0.3351\end{array}$ & $\begin{array}{l}r=0.7671 \\
p=0.0441^{*}\end{array}$ \\
\hline & & Deep learning approach motive in terms of learning content & $\begin{array}{l}r=-0.0181 \\
p=0.9691\end{array}$ & $\begin{array}{l}r=0.8728 \\
p=0.0103^{*}\end{array}$ \\
\hline & & Deep learning approach in terms of learning content & $\begin{array}{l}r=0.1853 \\
p=0.6908\end{array}$ & $\begin{array}{l}r=0.7783 \\
p=0.0393^{*}\end{array}$ \\
\hline & & Self-efficacy learning approach in terms of learning content & $\begin{array}{l}r=-0.1889 \\
p=0.6849\end{array}$ & $\begin{array}{l}r=0.9449 \\
p=0.0013^{*}\end{array}$ \\
\hline & & Deep-achieving approach to learning & $\begin{array}{l}r=0.0197 \\
p=0.9666\end{array}$ & $\begin{array}{l}r=0.8078 \\
p=0.0280^{*}\end{array}$ \\
\hline & & $\begin{array}{l}\text { Cooperative interdependent learning approach in terms of social } \\
\text { orientation }\end{array}$ & $\begin{array}{l}r=0.1101 \\
p=0.8142\end{array}$ & $\begin{array}{l}r=0.8994 \\
p=0.0058^{*}\end{array}$ \\
\hline \multirow[t]{5}{*}{ Team 3} & 9 & Deep learning approach motive in terms of learning content & $\begin{array}{l}r=0.7378 \\
p=0.0232^{*}\end{array}$ & $\begin{array}{l}r=0.5027 \\
p=0.1677\end{array}$ \\
\hline & & Deep learning approach in terms of learning content & $\begin{array}{l}r=0.6900 \\
p=0.0397^{*}\end{array}$ & $\begin{aligned} r & =0.8142 \\
p & =0.0075^{*}\end{aligned}$ \\
\hline & & $\begin{array}{l}\text { Achievement learning approach motive in terms of learning con- } \\
\text { tent }\end{array}$ & $\begin{array}{l}r=0.4546 \\
p=0.2188\end{array}$ & $\begin{array}{l}r=0.7199 \\
p=0.0287^{*}\end{array}$ \\
\hline & & Fear of failure in terms of surface approach to learning content & $\begin{array}{l}r=-0.9139 \\
p=0.0006^{\star}\end{array}$ & $\begin{array}{l}r=-0.6817 \\
p=0.0431^{*}\end{array}$ \\
\hline & & Independent learning approach in terms of social orientation & $\begin{array}{l}r=0.8306 \\
p=0.0056^{*}\end{array}$ & $\begin{aligned} r & =0.7638 \\
p & =0.0166^{*}\end{aligned}$ \\
\hline
\end{tabular}

Note. ${ }^{*} p \leq .05=$ significant at the $5 \%$ level

Table 5

Results of ANOVA for the Continuation Training (CT) Differences (Dependent Variable) Between the Three Teams (Least Squares Means, LSM, Used for Multiple Comparisons)

\begin{tabular}{cccccccc}
\hline & \multicolumn{2}{c}{ Team 1 } & \multicolumn{2}{c}{ Team 2 } & \multicolumn{3}{c}{ Team 3 } \\
& LSM & Std Error & LSM & Std Error & LSM & Std Error & $p$-value \\
\hline CT & 2.75 & 0.15 & 2.92 & 0.17 & 2.71 & 0.15 & 0.6087
\end{tabular}

while informal continuation training practices and associated impact were less obvious. ANOVA and post hoc comparisons indicate no statistically significant differences between the three teams regarding continuation training (CT) (Table 5). Thus one should not use continuation training (CT) to distinguish between the three teams (see Table 5).

Qualitative results supportive of quantitative analysis emphasise that self-directed teamwork and associated self-directed team learning inspired professional competence required to achieve air traffic control operational outcomes. In addition relationships found between teams' learning approaches and self-directed team performances were supportive of self-directed team learning. Self-directed learning emerged as individual and integrated formal and informal learning events and ex- periences. Informal learning, described as a preferred mode of learning, allowed team members to observe and reflect upon own actions and other's actions, thus allowing them to become actively involved in self-directed learning. Informal learning at individual level facilitated both task-specific and human factors learning. Training and learning initiatives identified in the investigated air traffic control organisation supported self-directed learning theories and practices. Self-directed learning was described by participants as a means to ensure compliance with individual and team competence/ performance requirements. Workplace performances in turn served as a self-directed learning input.

Collectively, the results suggest that self-directed team learning offered opportunities for individuals and teams to influ- 
ence team performances in an air traffic control work environment. This statement proposes a perceived relationship between self-directed team learning and air traffic control operational outputs. The nature of self-directed team learning's impact on the air traffic control work environment was illustrated by presenting identified and described individual and collective (team) views and dynamics. Impact of air traffic control team performances was explored in terms of identified teamwork characteristics, activities, dynamics, performance measures and focus areas and reflective practices.

A further understanding and appreciation of how these air traffic control teams sustained continued learning in the workplace was also probed. This inquiry uncovered continued learning expectations, environments, strategies, and benefits. For instance, formal air traffic control continuation training activities were noted in terms of contributions to continued aided learning and situational awareness in support of air traffic control knowledge, skills and attitudes. Furthermore, continuation training was managed generally in a formal/intentional manner, while informal continuation training practices and associated impact were less obvious.

We conclude that self-directed learning within the air traffic control teams had an impact on air traffic control operational outcomes, thus contributing towards a critical air traffic control goal - aviation safety. Findings of this study may encourage awareness from air traffic control service providers to stimulate, implement, manage and evaluate self-directed team learning within teams. Such self-directed team learning may also contribute towards improved teamwork and team performances. Again, a need may be identified to monitor and evaluate teamwork and team performances as a result of self-directed team learning investments. A self-directed team learning approach may thus contribute to aviation safety within the air traffic control community of practice.

\section{References}

Brockett, R. G., \& Hiemstra, R. (1991). Self-direction in adult learning: Perspectives on theory, research, and practice. London: Routledge.

Barbarino, M., \& Isaac, A. (2000). Development of team resource management in European air traffic control. In R. Fuller, N. Johnston, \& N. McDonald (Eds.), Human factors in aviation operations (pp. 269-277). Aldershot: Ashgate Publishing Limited.

Burgess, R. G. (1985). Strategies of educational research: Qualitative methods. Sussex: Falmer.

Cannon-Bowers, J. A., Salas, E., \& Converse, S. A. (1993). Shared mental models in expert decision making teams. In N. J. Castellan (Ed.), Current issues in individual and group decision making (pp. 221-246). Hillside, NJ: Erlbaum.

Dixon, N. M. (1994). The organizational learning cycle: How we can learn collectively. London: McGraw-Hill.

Flick, U. (1998). An introduction to qualitative research: Theory, method and applications. London: Sage.

Hammond, M., \& Collins, R. (1991). Self-directed learning: Critical practice. London: Kogan Page Limited.

Irwin, D., \& Rocine, V. (1994). Self-directed work teams coming to an organization near you. CMA Magazine, September, 10-15.

Joubert, C. G. (2006). Tracing the impact of self-directed team learning in an Air Traffic Control environment (Unpublished doctoral thesis). University of Pretoria, South Africa.
Leroux, M. (1995). ERATO: Cognitive engineering applied to ATC. In R. Fuller, N. Johnston, \& N. McDonald (Eds.), Human factors in aviation operations (pp. 89-94). Aldershot, Great Britain: Ashgate.

MacLeod, N. (2001). Training design in aviation. Aldershot, Great Britain: Ashgate.

McMillan, J. H., \& Schumacher, S. (2001). Research in education: A conceptual introduction (5th ed.). New York: Addison Wesley Longman.

Meyer, M. (1999). Managing human resource development: An outcomes-based approach. Durban, South Africa: Butterworths.

Mezirow, J.D. (1981). A critical theory of adult learning and education. Adult Education Quarterly, 32, 3-24.

Miller, G., \& Dingwall, R. (1997). Context and method in qualitative research. London: Sage.

Ober, S., Yanowitz, J., \& Kantor, D. (1996). Creating results through team learning. Management Decision, 34, 49-50.

Rogers, A. (2002). Teaching adults (3rd ed.). Buckingham: Open University Press.

Salas, E., Bowers, C. A., \& Edens, E. (2001). Improving teamwork in organizations: Applications of resource management training. Mahwah, NJ: Lawrence Erlbaum Associates.

Schaap, P. (2000). Die ontwikkeling van ' $n$ psigometriese instrument om die leerbenaderings van volwassenes te bepaal. (Development of a psychometric instrument to determine the learning approaches of adults.)(Unpublished doctoral thesis). University of Pretoria, South Africa.

Silverman, S. L., \& Casazza, M. E. (2000). Learning and development: Making connections to enhance teaching. San Francisco, CA: Jossey-Bass.

Smith-Jentsch, K. A., Kraiger, K., Salas, E., \& Cannon-Bowers, J. A. (1999, May). Teamwork in the control tower: How does it differ from cockpit resource management? Paper presented at the 10th international symposium on aviation psychology, Columbus, $\mathrm{OH}$.

Smith-Jentsch, K. A., Zeisig, R. L., Cannon-Bowers, J. A., \& Salas, E. (1997, April). Defining and training tower cab teamwork. Paper presented at the 9th international symposium on aviation psychology, Ohio State University.

Swanson, R. A., \& Holton, E. F. (1997). Human resource development: Research handbook, linking research and practice. San Francisco, CA: Berret Koehler.

Tashakkori, A., \& Teddlie, C. (1998). Mixed methodology: Combining qualitative and quantitative approaches. Applied Social Research Methods Series, 46. Thousand Oaks, CA: Sage.

Teddlie, C., \& Tashakkori, A. (2003). Major issues and controversies in the use of mixed methods in the social and behavioural science. In A. Tashakkori \& C. Teddlie, C. (Eds.), The handbook of mixed methods in the social and behavioural research (pp. 3-50). London, England: Sage.

Williams, R. (2004). Self-directed work teams: A competitive advantage. Quality Digest. Retrieved from http://www. qualitydigest.com

Zimmerman, B. J. (1990). Self-regulated learning and academic achievement: An overview. Educational Psychologist, 24, 2-17. 


\section{Acknowledgements}

This research was authorized by the South African Air Force. Any opinions, findings, conclusions, and recommendations expressed in this publication are those of the authors and do not necessarily reflect the views of the South African Air Force. 
Maree et al. 